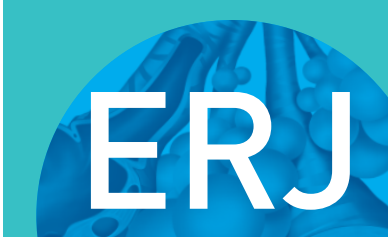

open research

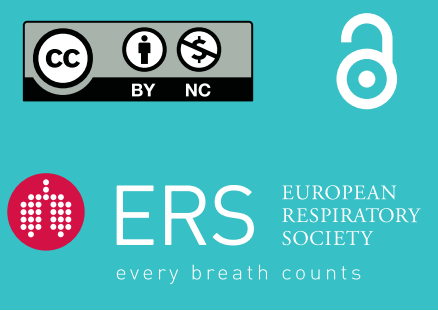

\section{Allergic disease and risk of stress in pregnant women: a PreventADALL study}

\author{
Caroline-Aleksi Olsson Mägi (1) 1,2, Anders Bjerg Bäcklund (ib) ${ }^{1,2}$, \\ Karin Lødrup Carlsen ${ }^{3,4}$, Catarina Almqvist ${ }^{2,5}$, Kai-Håkon Carlsen ${ }^{3,4}$, \\ Berit Granum ${ }^{3,4}$, Guttorm Haugen ${ }^{3,6}$, Katarina Hilde ${ }^{3,6}$, Oda C. Lødrup Carlsen ${ }^{3}$, \\ Christine Monceyron Jonassen ${ }^{7,8}$, Eva Maria Rehbinder '(10,9, Katrine D. Sjøborg ${ }^{30}$, \\ Håvard Skjerven ${ }^{3,4}$, Anne Cathrine Staff (103,6, Riyas Vettukattil (10,4, \\ Cilla Söderhäll ${ }^{1}$ and Björn Nordlund $\mathbb{1}^{1,2}$ on behalf of the study group ${ }^{11}$
}

Affiliations: ${ }^{1}$ Dept of Women's and Children's Health, Karolinska Institutet, Stockholm, Sweden. ${ }^{2}$ Astrid Lindgren Children's Hospital, Karolinska University Hospital, Stockholm, Sweden. ${ }^{3}$ Faculty of Medicine, Institute of Clinical Medicine, University of Oslo, Oslo, Norway. ${ }^{4}$ Division of Paediatric and Adolescent Medicine, Oslo University Hospital, Oslo, Norway. ${ }^{5}$ Dept of Medical Epidemiology and Biostatistics, Stockholm, Sweden. ${ }^{6}$ Division of Obstetrics and Gynaecology, Oslo University Hospital, Oslo, Norway. ${ }^{7}$ Genetic Unit, Centre for Laboratory Medicine, Østfold Hospital Trust, Kalnes, Norway. ${ }^{8}$ Faculty of Chemistry, Biotechnology and Food Science, Norwegian University of Life Sciences, Ås, Norway. ${ }^{9}$ Dept of Dermatology and Venerology, Oslo University Hospital, Oslo, Norway. ${ }^{10}$ Dept of Obstetrics and Gynaecology, Østfold Hospital Trust, Kalnes, Norway. ${ }^{11} \mathrm{~A}$ list of the PreventADALL study group members and their affiliations can be found in the Acknowledgements section.

Correspondence: Caroline-Aleksi Olsson Mägi, Dept of Women's and Children's Health, Karolinska Institutet, Karolinska vägen 37A, QB:84, Solna, Stockholm 171, Sweden. E-mail: caroline-aleksi.olsson.magiaki.se

\section{ABSTRACT}

Background: Maternal stress during pregnancy may negatively affect the health of mother and child. We therefore aimed to identify the proportion of women reporting high maternal stress in mid and late pregnancy and explore whether symptoms of maternal allergic disease are associated with perceived maternal stress in late pregnancy.

Method: The population-based Preventing Atopic Dermatitis and Allergy in Children (PreventADALL) study enrolled 2697 pregnant women at their 18-week routine ultrasound examination in Norway and Sweden. Information about sociodemographic factors, symptoms and doctor-diagnosed asthma, allergic rhinitis, atopic dermatitis, food allergy, and anaphylaxis and stress using the 14-item perceived stress scale (PSS) was collected at 18 weeks (mid) and 34 weeks (late) pregnancy. High stress was defined as a PSS score $\geqslant 29$. Scores were analysed using multivariate logistic and linear regression.

Results: Among the 2164 women with complete PSS data, 17\% reported asthma, 20\% atopic dermatitis, 23\% allergic rhinitis, $12 \%$ food allergy and $2 \%$ anaphylaxis. The proportion of women reporting high stress decreased from $15 \%$ at mid to $13 \%$ at late pregnancy $(\mathrm{p}<0.01)$. The adjusted odds ratio for high stress in late pregnancy was 2.25 (95\% CI 1.41-3.58) for self-reported symptoms of asthma, 1.46 (95\% CI 1.02-2.10) for allergic rhinitis and 2.25 (95\% CI 1.32-3.82) for food allergy. A multivariate linear regression model confirmed that symptoms of asthma ( $\beta$ coefficient $2.11 ; 0.71-3.51$ ), atopic dermatitis $(\beta$ coefficient $1.76 ; 0.62-2.89)$ and food allergy ( $\beta$ coefficient $2.24 ; 0.63-3.84$ ) were independently associated with increased PSS score.

Conclusion: Allergic disease symptoms in pregnancy were associated with increased stress, highlighting the importance of optimal disease control in pregnancy.

@ERSpublications

In this population-based study, high stress was reported by $15 \%$ in mid-pregnancy and in $13 \%$ at late pregnancy. High stress in late pregnancy was associated with symptoms of asthma, allergic rhinitis and food allergy. https://bit.ly/3faKmwh

Cite this article as: Olsson Mägi C-A, Bjerg Bäcklund A, Lødrup Carlsen K, et al. Allergic disease and risk of stress in pregnant women: a PreventADALL study. ERJ Open Res 2020; 6: 00175-2020 [https://doi.org/10.1183/23120541.00175-2020].

This article has supplementary material available from openres.ersjournals.com

Received: 7 April 2020 | Accepted after revision: 23 July 2020

Copyright $\odot$ ERS 2020. This article is open access and distributed under the terms of the Creative Commons Attribution Non-Commercial Licence 4.0. 


\section{Introduction}

In maternal healthcare, risk assessments are performed during pregnancy to detect factors that may negatively impact both maternal and fetal health [1]. Stress can be defined as an individual, nonspecific response of the body to various demands of the inner and outer environment [2]. Stress has been suggested to be the first step to depressive and anxiety-like symptoms [3], and the prevalence seems to be similar in pregnant and non-pregnant women [4]. However, whereas depression and anxiety can be identified using established diagnostic tools, similar assessments are lacking for stress. Cohen's perceived stress scale (PSS) is a validated method to capture maternal stress $[5,6]$, and cut-off for high stress levels has been used to define groups of individuals perceiving higher stress [7].

Pregnant women's perceptions of stress may be heterogeneous with respect to geographical differences and sociodemographic factors [8], and can be associated with previous and current health status [9, 10]. However, the relationship between high perceived stress, life events and chronic disease in pregnancy are to date not fully understood. Identifying prenatal risk factors and managing stress in pregnancy may reduce adverse health effects in both mother and offspring [11, 12].

Worldwide, asthma is among the most common chronic diseases in pregnant women [13]. The course of asthma in pregnancy is unpredictable and appears to fluctuate in the majority of women [14]. Atopic dermatitis is the most common skin disorder in pregnant women, and symptoms may worsen in pregnancy [15]. The links between stress and symptoms of allergic diseases like asthma, atopic dermatitis, allergic rhinitis and food allergy during pregnancy are not established. We hypothesised that symptoms of allergic diseases would increase levels of perceived maternal stress during pregnancy. The aims of this study were to estimate the prevalence of women reporting high maternal stress in mid and late pregnancy and explore whether symptoms of maternal allergic disease are associated with high perceived maternal stress in late pregnancy.

\section{Methods}

\section{Study design and recruitment}

The present study is part of the Preventing Atopic Dermatitis and Allergy in Children (PreventADALL) study. PreventADALL is a Nordic multicentre, $2 \times 2$ factorial, interventional birth cohort study with two objectives: to investigate the effect of primary prevention of allergic diseases by early skin care and early complementary food introduction, as described in detail elsewhere [16]; and secondly to explore early life factors associated with non-communicable disease development. Pregnant women were enrolled in connection with the 18-week routine ultrasound scanning from December 2014-October 2016, at Oslo University Hospital and Østfold Hospital Trust in Norway and at Karolinska University Hospital and collaborating obstetrical units in Stockholm, Sweden. Women with singleton or twin pregnancies and sufficient language skills (Norwegian or Swedish) were invited to participate. Women were excluded if they were planning to move far from any of the study sites shortly after inclusion or if they had severe fetal or maternal disease.

Their newborn infants included at birth [16] are not part of the present study. The women provided informed written consent prior to enrolment. Ethical approval was granted by the regional ethics committees in Norway (2014/518) and Sweden (2014/2242-31/4). Clinical Trial Registration: ClinicalTrials.gov number: NCT02449850.

\section{Subjects}

A total of 2697 pregnant women were enrolled constituting 2701 pregnancies, with four women participating with two different pregnancies. The present study included all 2164 women who completed information on PSS in mid (18th week of gestation) and late (34th week of gestation) pregnancy (figure S1).

\section{Data collection}

The inclusion visit conducted at enrolment between 16 and 22 pregnancy weeks involved a short interview about current and previous pregnancies as well as measurements of height, weight and blood pressure.

Two electronic questionnaires were sent by e-mail, the first in mid-pregnancy, shortly after study inclusion, and the second in late pregnancy. The first questionnaire collected background information on women's socio-demographics, previous and current health status and maternal stress. Further, histories of doctor-diagnosed asthma, atopic dermatitis, allergic rhinitis and food allergy were collected. In late pregnancy a second questionnaire was sent to capture information about the father and changes from mid-pregnancy corresponding to socio-demographics, women's stress, medical history of allergic disease and symptoms. The majority of questions had been used in other birth cohort studies [17]. Maternal stress was assessed with Cohen's PSS (14 items) scored from 0 to 4 for each item with a total maximum score of 56 , 
as previously reported in pregnant women [18]. Higher score corresponds to higher perceived stress, as it measures how often in the past month the woman felt their life was "unpredictable, uncontrollable or overloaded" [5]. The completed questionnaires were submitted electronically and data stored at University of Oslo, University Centre for Information Technology (USIT).

\section{Definitions and outcomes}

\section{Socio-demographics}

An annual family income of 600000 Norwegian or Swedish kroner (NOK/SEK) or less was categorised as a low income. High school as the highest achieved education was defined as low education. Unemployment was defined as being a student, on parental leave, having an internship or being unemployed. Single marital status was defined as living alone, being widowed or separated from partner. Women reporting previous pregnancy had been pregnant at least once before but had not necessarily given birth.

\section{Maternal health}

The presence of allergic disease was defined as self-reported doctor-diagnosed asthma, allergic rhinitis, atopic dermatitis and food allergy at mid and late pregnancy. Reported symptoms of and treatment for allergic disease were restricted to women who had reported doctor diagnosis for each relevant disease at mid and late pregnancy. Treatment of asthma was categorised by any use of inhaled corticosteroids (ICS), for atopic dermatitis by use of skin emollients and topical treatment with tacrolimus monohydrate, pimecrolimus and corticosteroids, and for allergic rhinitis by any use of nasal antihistamine or steroids for at least the last 2 weeks. Use of analgesics corresponded to any use of paracetamol, nonsteroidal anti-inflammatory drug or acetylsalicylic acid between mid- and late-pregnancy questionnaires.

Stress

High perceived stress was defined by a PSS score of $29 / 56$ or more, equal to $1 \mathrm{SD}$ of sample mean in the PreventADALL study.

\section{Statistical analysis}

All analyses were performed using SPSS statistics version 25 (IBM, Chicago, IL, USA). Continuous variables were presented as mean and $\mathrm{SD}$, categorical variables as number and percentages (\%) and recoded into binary variables when necessary. Differences between categorical variables were analysed using Chi-squared or univariate regression analysis and presented with a p-value or odds ratio with $95 \%$ confidence intervals. Statistically significant factors in univariate analysis were included in multivariate regression Models I and II, respectively. Multivariate binary regressions with adjusted odds ratio were used to compare symptoms of allergic disease between women with high stress and the reference group of women with low stress at mid and late pregnancy. Univariate and multivariate linear regression analyses were used to further study associations identified in binary regression analyses. The results of linear regression are presented as unstandardised $\beta$ coefficient with $95 \%$ confidence intervals and $p$-values. The association of stress and diagnosis of allergic disease with or without symptoms was assessed in a subgroup analysis. All analyses for statistical significance were at the 5\% significance level.

\section{Results}

The characteristics of the 2164 women at inclusion are presented in table 1 . The mean age was 32 years, the majority were employed (91\%) and 55\% had undergone a previous pregnancy.

Doctor-diagnosed asthma ever in life was self-reported in mid pregnancy by 365 women (17\%) 63 of whom reported use of ICS, one had used oral corticosteroids for asthma in the last 2 weeks and none reported use of biologics, including anti-IgE. Atopic dermatitis was reported by $20 \%$, allergic rhinitis by $23 \%$ and food allergy by $14 \%$ of the women. For food allergy, most reported reactions to nuts other than peanut $(6.7 \%)$ followed by fruits and vegetables $(5.5 \%)$, while $3 \%$ reported having an anaphylactic reaction to any allergen some time in their life.

The mean (SD) PSS score was 21.1 (7.2) in mid pregnancy and 20.3 (7.3) in late pregnancy. The proportion of women with high stress according to definition decreased from $15 \%$ to $13 \%$ between mid and late pregnancy $(\mathrm{p}<0.01)$, while $7 \%$ had high stress at both time points and $20 \%$ at any time point.

Univariate analysis of maternal factors associated with high stress in mid and late pregnancy are presented in table 2. High stress at any time point was significantly associated with low income, with an OR 1.92 (95\% CI 1.40-2.64) in late pregnancy and with at least one previous pregnancy with an OR 1.64 (95\% CI 1.27-2.12). Possible risk factors for onset of high stress after mid-pregnancy were doctor's diagnosis of allergic rhinitis (OR 1.54, 95\% CI 1.14-2.07), use of analgesics (OR 1.57, 95\% CI 1.22-2.01), moving to a 


\section{TABLE 1 Background characteristics of enrolled pregnant women with self-reported low and high stress}

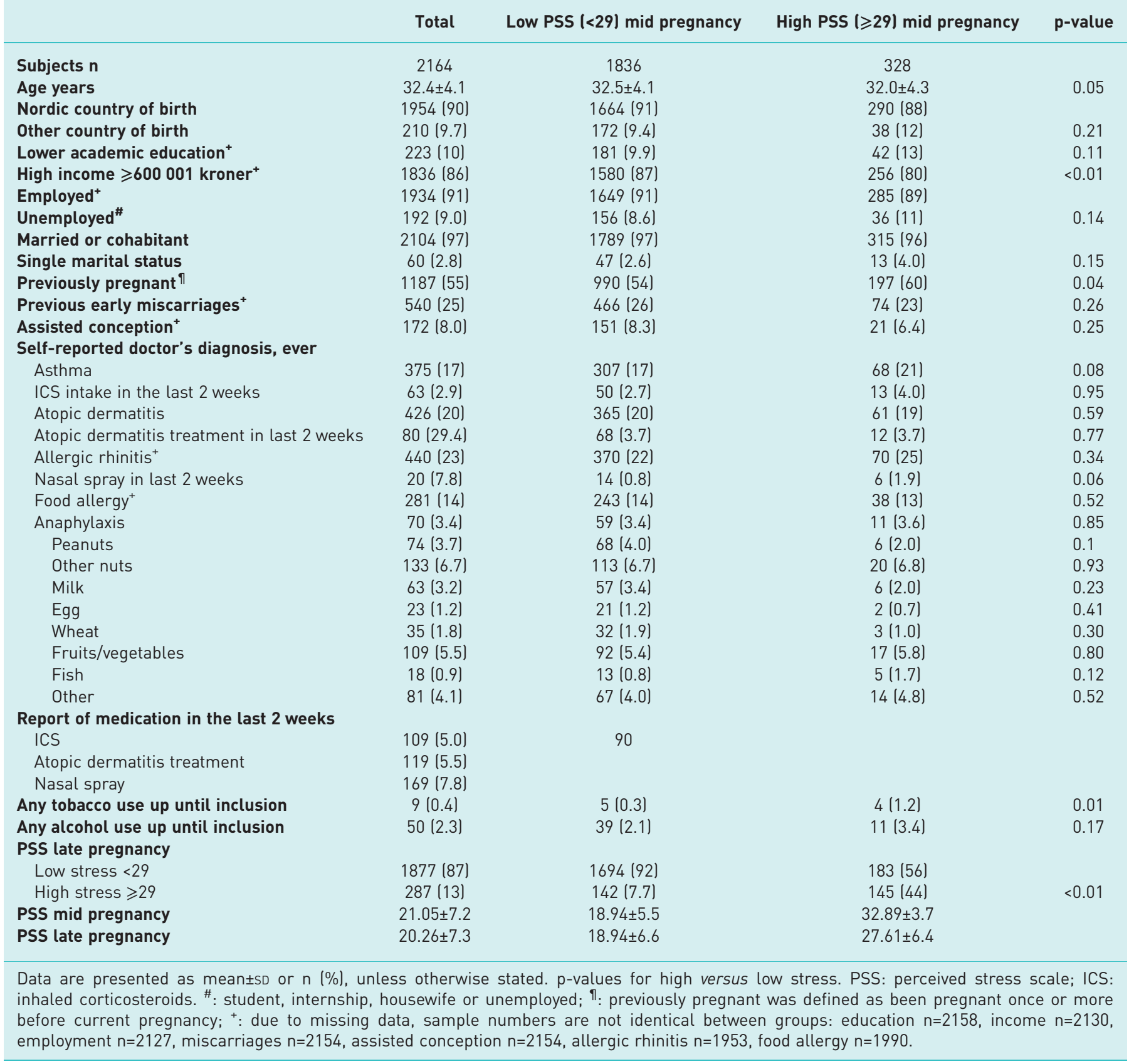

new residence (OR 1.72, 95\% CI 1.20-2.45), changes in employment (OR 1.75, 95\% CI 1.08-2.85), high school only (OR 1.9, 95\% CI 1.34-2.69) and unemployment (OR 2.10, 95\% CI 1.46-3.02).

Symptoms from mid to late pregnancy was reported by 108 women with asthma, 170 with atopic dermatitis, 244 with allergic rhinitis and 82 with food allergy. Five women reported incident asthma symptoms in late pregnancy, i.e. without previous diagnosis or symptoms reported at mid pregnancy, while 11 reported first-time atopic dermatitis symptoms and eight women first-time allergic rhinitis symptoms. In late pregnancy, 48 of 108 women had used ICS. The use of ICS in the last 2 weeks was significantly associated with high stress in late pregnancy but not in mid pregnancy, in univariate analyses (table 2). Reporting symptoms of both asthma and allergic rhinitis, as well as of both asthma and food allergy, were significantly associated with high stress (Models: I and II, table 3). Further, symptoms of asthma as well as food allergy after mid trimester were significantly associated with high stress in late pregnancy as shown in table 3. Model 


\begin{tabular}{|c|c|c|c|c|c|c|}
\hline & \multicolumn{3}{|c|}{$\begin{array}{l}\text { High PSS }(\geqslant 29] \\
\text { mid-pregnancy" }\end{array}$} & \multicolumn{3}{|c|}{$\begin{array}{l}\text { High PSS ( } \geqslant 29) \text { late } \\
\text { pregnancy }^{+}\end{array}$} \\
\hline & n $(\%)$ & OR & $95 \% \mathrm{Cl}$ & n (\%) & OR & $95 \% \mathrm{Cl}$ \\
\hline Other country of birth & $38(12)$ & 1.27 & $(0.87-1.84)$ & $31(11)$ & 1.15 & $(0.77-1.72)$ \\
\hline High school only & 42 (13) & 1.34 & (0.94-1.92) & $47(16)$ & 1.90 & $(1.34-2.69)$ \\
\hline Low income & $65(20)$ & 1.76 & (1.30-2.39) & $61(22)$ & 1.92 & $(1.40-2.64)$ \\
\hline Unemployed $^{\S}$ & $36(11)$ & 1.34 & $(0.91-1.96)$ & $44(16)$ & 2.10 & $(1.46-3.02)$ \\
\hline Single marital status & $13(4.0)$ & 1.57 & (0.84-2.94) & $14(4.9)$ & 2.04 & (1.11-3.77) \\
\hline Previously pregnant ${ }^{f}$ & $197(60)$ & 1.29 & $(1.01-1.63)$ & $187(65)$ & 1.64 & $(1.27-2.12)$ \\
\hline Early miscarriages & 77 (23) & 1.12 & (0.84-1.48) & 77 (27) & 1.12 & $(0.84-1.48)$ \\
\hline Late miscarriages & $10(3.0)$ & 1.61 & (0.79-3.28) & $10(3.5)$ & 1.90 & $(0.93-3.87)$ \\
\hline Assisted conception & $21(6.4)$ & 0.78 & (0.52-1.19) & $19(6.6)$ & 0.78 & $(0.49-1.31)$ \\
\hline \multicolumn{7}{|c|}{ Self-reported doctor's diagnosis ever } \\
\hline Asthma & $68(21)$ & 1.30 & $(0.97-1.75)$ & $60(21)$ & 1.31 & $(0.96-1.79)$ \\
\hline ICS last two weeks & $13(4.0)$ & 1.47 & (0.79-2.75) & $17(6.0)$ & 3.08 & $(1.77-5.34)$ \\
\hline Atopic dermatitis & $61(19)$ & 0.92 & $(0.68-1.25)$ & $58(20)$ & 1.04 & $(0.76-1.42)$ \\
\hline $\mathrm{AD}$ treatment last 2 weeks & $12(4.0)$ & 0.99 & (0.53-1.85) & $5(2.0)$ & 1.13 & $(0.43-2.94)$ \\
\hline Allergic rhinitis & $70(25)$ & 1.16 & $(0.86-1.55)$ & $73(30)$ & 1.54 & $(1.14-2.07)$ \\
\hline Nasal spray last 2 weeks & $6(2.0)$ & 1.87 & $(0.66-5.29)$ & $6(2.0)$ & 2.01 & $(0.86-4.73)$ \\
\hline Food allergy & $38(13)$ & 0.89 & (0.62-1.28) & $39(15)$ & 1.09 & $(0.75-1.57)$ \\
\hline \multicolumn{7}{|l|}{ Events in pregnancy } \\
\hline Use of analgesic & & & & 152 (54) & 1.57 & $(1.22-2.01)$ \\
\hline Moved to new residence & & & & $44(16)$ & 1.72 & $(1.20-2.45)$ \\
\hline Changes in employment & & & & $22(7.7)$ & 1.75 & (1.08-2.85) \\
\hline
\end{tabular}

PSS: perceived stress scale; ICS: inhaled corticosteroids. ${ }^{\#}: \mathrm{n}=2164 ;{ }^{\text {ๆ }}: \mathrm{n}=328 ;{ }^{+}: \mathrm{n}=287 ;{ }^{\text {§ }}$ : student, internship, housewife or unemployed; $f$ : previously pregnant was defined as been pregnant once or more before current pregnancy.

I adjusted for factors at inclusion of lower income and previous pregnancy and Model II for factors at late pregnancy of moving to new residence, changes in employment and use of analgesics.

Using PSS score as a continuous variable, high stress was associated with symptoms of asthma, atopic dermatitis and food allergy in model I (adjusted for factors at inclusion). In Model II (adjusting for factors at late pregnancy), the PSS score was significantly associated with symptoms of asthma, atopic dermatitis and food allergy on their own, but only with the symptoms of atopic dermatitis when combined with asthma (table 4).

The risk of high stress increased among women with doctor-diagnosed asthma who had asthma symptoms compared to no symptoms in pregnancy (OR 2.97, 95\% CI 1.30-6.74) (table 5). Neither symptoms nor doctor diagnosis of atopic dermatitis and allergic rhinitis, nor food allergy were significantly associated with high stress compared to women with no symptoms and relevant allergic disease.

\section{Discussion}

In this population-based study including pregnant women, high stress was reported by $15 \%$ in mid pregnancy, in $13 \%$ in late pregnancy and in $7 \%$ in both mid and late pregnancy. High stress in late pregnancy was associated with symptoms of asthma, atopic dermatitis, allergic rhinitis and food allergy.

The finding that $15 \%$ reported high perceived stress in mid pregnancy and $13 \%$ in late pregnancy is, to our knowledge, the first report from a large population-based study using the validated Cohen's PSS in pregnant women within the Nordic countries. Our findings are in line with high perceived stress in $17 \%$ of pregnant women in Canada [19], but lower than the median PSS-10 score of 26/40 in the Swedish Born into Life study including 92 pregnant at gestational age 26-28 weeks [20] and high stress in 33\% of pregnant women in Saudi Arabia [21]. The operational cut-off value for high stress in our study has been used elsewhere [22, 23]. We found that low education, low income and unemployed status increased the risk of high stress in late pregnancy (suggesting that a poor financial situation during pregnancy is a stressor [24]), as did moving to a new residence and changes in employment. Further, use of analgesics increased the risk of incident high stress, suggesting that pain rather than use of analgesics may be the stressor. Although maternal smoking and alcohol use have been associated with increased stress $[21,25,26]$, in our study very few individuals reported such exposure. 


\begin{tabular}{|c|c|c|c|c|c|c|c|}
\hline & \multirow[t]{2}{*}{$\begin{array}{c}\text { Subjects } \\
\mathrm{n}\end{array}$} & \multicolumn{2}{|c|}{$\begin{array}{c}\text { High PSS }(\geqslant 29) \text { late } \\
\text { pregnancy }\end{array}$} & \multicolumn{2}{|c|}{$\begin{array}{c}\text { Model I high } \\
\text { PSS I } \geqslant 29] \\
\text { late pregnancy }\end{array}$} & \multicolumn{2}{|c|}{$\begin{array}{l}\text { Model II high } \\
\text { PSS I } \geqslant 29] \\
\text { late pregnancy }\end{array}$} \\
\hline & & $\begin{array}{l}\text { crude } \\
\text { OR }\end{array}$ & $95 \% \mathrm{Cl}$ & $\mathrm{aOR}$ & $95 \% \mathrm{Cl}$ & $\mathrm{aOR}^{+}$ & $95 \% \mathrm{Cl}$ \\
\hline Asthma with symptoms & 26 & 2.18 & $1.38-3.46$ & 2.25 & $1.41-3.58$ & 2.07 & $1.29-3.30$ \\
\hline $\begin{array}{l}\text { Atopic dermatitis with } \\
\text { symptoms }\end{array}$ & 30 & 1.45 & $0.96-2.19$ & 1.49 & $0.98-2.27$ & 1.42 & $0.93-2.15$ \\
\hline $\begin{array}{l}\text { Allergic rhinitis with } \\
\text { symptoms }\end{array}$ & 42 & 1.43 & $1.00-2.05$ & 1.46 & $1.02-2.10$ & 1.42 & $0.98-2.03$ \\
\hline Food allergy with symptoms & 20 & 2.19 & $1.30-3.69$ & 2.25 & $1.32-3.82$ & 2.06 & $1.22-3.49$ \\
\hline $\begin{array}{l}\text { Symptoms of asthma and } \\
\text { atopic dermatitis }\end{array}$ & 30 & 1.45 & $0.96-2.20$ & 1.49 & $0.98-2.27$ & 1.41 & $0.93-2.15$ \\
\hline $\begin{array}{l}\text { Symptoms of asthma and } \\
\text { allergic rhinitis }\end{array}$ & 42 & 1.48 & $1.03-2.12$ & 1.52 & $1.06-2.19$ & 1.47 & $1.02-2.11$ \\
\hline $\begin{array}{l}\text { Symptoms of asthma and food } \\
\text { allergy }\end{array}$ & 16 & 1.96 & $1.11-3.46$ & 2.05 & $1.14-3.66$ & 1.85 & $1.04-3.30$ \\
\hline
\end{tabular}

PSS: perceived stress scale. " $\mathrm{n}=2164 ;$ १: adjusted for factors at inclusion: low income, previously pregnant; ${ }^{+}$: adjusted for factors at late pregnancy: moved to new residence, changes in employment and use of analgesics.

Our results indicate that having asthma symptoms between mid and late pregnancy increased the risk of high stress in the general population and among symptomatic versus asymptomatic women with doctor-diagnosed asthma. The association of stress with symptoms of asthma remains insufficiently understood. Environmental stressors may act on a pathway of endogenous mechanisms via the release glucocorticoids and pro-inflammatory cytokines [27], thereby potentially promoting symptoms of underlying allergic disease. Among our participating women with asthma symptoms from mid to late pregnancy, five women reported first-time symptoms and only 48 out of 108 (44\%) women used ICS by late pregnancy. Although we are unaware of the exact prescribed doses before and during pregnancy, our results indicate that pregnant women with asthma may be undertreated. Pregnant women with poor asthma control in pregnancy risk adverse outcomes in both themselves and their fetuses [28]. Guidelines highlight continued medication and symptom control in pregnancy. This is considered to be both

TABLE 4 Simple and adjusted linear regression of stress and symptoms of allergic disease in late pregnancy with unstandardised $\beta$ coefficient $^{\#}$

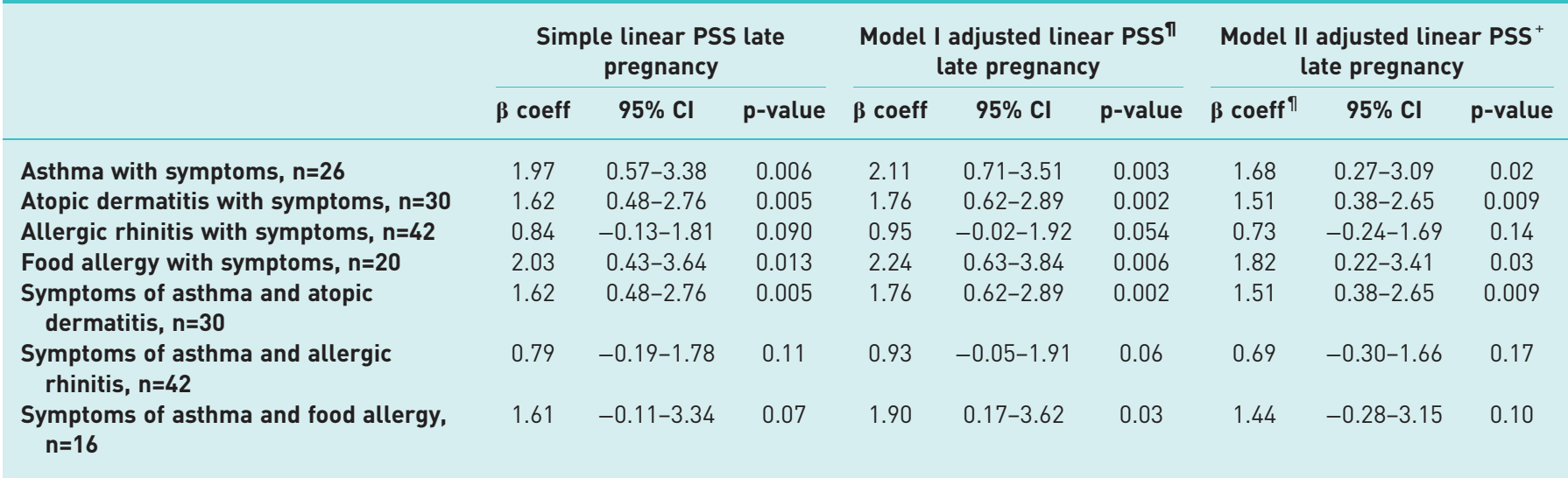

PSS: perceived stress scale. ${ }^{\#}: \mathrm{n}=2164 ;{ }^{\uparrow}$ : adjusted for factors at inclusion: income, previously pregnant; ${ }^{+}$: adjusted for factors at late pregnancy: moved to new residence, changes in employment and use of analgesics. 


\begin{tabular}{|c|c|c|c|}
\hline & $\begin{array}{l}\text { Low PSS } \mid<29] \\
\text { late pregnancy }\end{array}$ & $\begin{array}{l}\text { High PSS }(\geqslant 29) \\
\text { late pregnancy }\end{array}$ & OR $(95 \% \mathrm{CI})$ \\
\hline Asthma without symptoms & $78(51)$ & $9(26)$ & \\
\hline Asthma with symptoms & $76(49)$ & $26(74)$ & $2.97(1.30-6.74)$ \\
\hline Atopic dermatitis without symptoms & $43(23)$ & $9(24)$ & \\
\hline Atopic dermatitis with symptoms & 145 (77) & $29(76)$ & $0.96(0.42-2.17)$ \\
\hline Allergic rhinitis without symptoms & 35 (19) & $11(26)$ & \\
\hline Allergic rhinitis with symptoms & 148 (81) & $32(74)$ & $0.69(0.32-1.50)$ \\
\hline Food allergy without symptoms & $59(50)$ & $7(29)$ & \\
\hline Food allergy with symptoms & $58(50)$ & $17(71)$ & $2.47(0.95-6.40)$ \\
\hline
\end{tabular}

important and safe [29, 30], even if poor adherence and changes in medical prescriptions during pregnancy occur [31]. A French study investigating asthma medication in pregnancy showed a decrease in fixed combination drugs and an increase in use of ICS [31].

To our knowledge, the association between symptoms of atopic dermatitis and food allergy and high stress in late pregnancy are novel findings. Our finding that high stress was significantly associated with atopic dermatitis is supported by an observational study emphasising that $\sim 52 \%$ of women may report worsening atopic dermatitis symptoms during pregnancy [32]. Likewise, our finding that symptomatic food allergy was associated with high stress in pregnant women is supported by the reported reduced quality of life in patients with food allergy [33]. During pregnancy, women are often advised to eat a healthy diet [34], but specific individual support on food allergy and diets can be hard to provide [35, 36]. Food allergies may further restrict the diet and possibly explain our findings of high stress in late pregnancy in these women. Collectively, our findings suggest that symptoms of asthma and other allergic diseases, rather than the diagnosis per se, increase the risk of high stress and point to the importance of optimal disease management throughout pregnancy [29].

In PreventADALL, we found several socioeconomic factors associated with high perceived stress in late pregnancy that were not present in mid pregnancy. These included lower educational attainment level, lower income and unemployment. Our findings are in line with previous studies, suggesting that a poor financial situation during pregnancy is a stressor [24]. One theory gaining attention is the theory of allostatic load or the cumulative psychological and physiological impact of stress over a life course [37]. This theory provides a biological mechanism linking psychological stress with promotion of immune dysregulation. Further, greater and more extended inflammatory responses to acute stress have been reported among groups with lower socioeconomic status [38], which can link to our study results and explain the association between troublesome asthma/allergy and stress.

A strength of the present study is a relatively large study population recruited from the general population and the prospective design where women reported perceived stress and detailed information about previous and current health twice during their pregnancy. We also applied a previously used definition of perceived stress to define high stress in the pregnant women $[13,29]$, together with linear analysis of the PSS variable. High perceived stress is likely to be associated with symptoms of allergic disease in similar populations. However, PSS is a validated measurement but not a diagnostic instrument [27], so the generalizability of our results should be done with caution. The following limitations should be noted. The proportion of participants with a history of allergic diseases indicates some bias towards allergy in our population. Limited information about symptoms or asthma control score makes it difficult to assess the severity of the allergic response to stress. Pregnancy complications have been suggested to elevate stress in pregnancy [39]. In our study, pregnancy complications both in mid and late pregnancy were not included in the analysis since self-reported complications were low, and these need to be further investigated based on complementary information from medical records. 
Implications of our findings suggest that high perceived stress is common, and several modifiable factors associated with high stress should be addressed during pregnancy. Stress-reducing strategies appear relevant for maternal healthcare programmes.

\section{Conclusion}

Perceived high stress was reported by $15 \%$ in mid pregnancy and $13 \%$ in late pregnancy, and was associated with lower socioeconomic status and previous pregnancies. In late pregnancy, symptomatic doctor-diagnosed asthma, allergic rhinitis and food allergy were independently and in combination associated with high stress. Our findings highlight the importance of identifying stress in pregnant women and employing strategies for stress reduction and controlling allergic symptoms in maternal healthcare.

Acknowledgements: We sincerely thank all participants and health personnel working with PreventADALL in Norway and Sweden, and the following funders that have contributed to this study: Swedish Heart and Lung foundation, Swedish Asthma and Allergy Association, Karolinska institutet SFO-V, Konsul Th. C Bergh Foundation, Hesselman Research Foundation, Vårdalstiftelsen, Swedish Research Council.

The PreventADALL study group: Anna Undeman Asarnoj (Dept of Women's and Children's Health, Karolinska Institutet, and Astrid Lindgren Children's Hospital, Karolinska University Hospital, Stockholm, Sweden), Peder Annæus Granlund (Faculty of Medicine, Institute of Clinical Medicine, University of Oslo, and Dept of Toxicology and Risk Assessment, Norwegian Institute of Public Health, Oslo, Norway), Hrefna Katrín Gudmundsdóttir (Faculty of Medicine, Institute of Clinical Medicine, University of Oslo, Oslo, Norway), Sandra Götberg (Dept of Women's and Children's Health, Karolinska Institutet, and Astrid Lindgren Children's Hospital, Karolinska University Hospital, Stockholm, Sweden), Monica Hauger Carlsen (Faculty of Medicine, Institute of Clinical Medicine, University of Oslo, Oslo, Norway), Angelica Johansen Winger (Division of Paediatric and Adolescent Medicine, Oslo University Hospital, Oslo, Norway), Nora Nilsson (Astrid Lindgren Children's Hospital, Karolinska University Hospital, Stockholm, Sweden), Unni C. Nygaard, Knut Rudi (Faculty of Chemistry, Biotechnology and Food Science, Norwegian University of Life Sciences, Ås, Norway), Ingebjørg Skrindo (Division of Paediatric and Adolescent Medicine, Oslo University Hospital, Oslo, Norway), Carina M. Saunders (Faculty of Medicine, Institute of Clinical Medicine, University of Oslo, Oslo, Norway), Sandra G. Tedner (Dept of Women's and Children's Health, Karolinska Institutet, and Astrid Lindgren Children's Hospital, Karolinska University Hospital, Stockholm, Sweden), Magdalena R. Værnesbranden (Dept of Obstetrics and Gynaecology, Østfold Hospital Trust, Kalnes, Norway) and Johanna Wiik (Genetic Unit, Centre for Laboratory Medicine, Østfold Hospital Trust, Kalnes, Norway).

Support statement: This study was supported by Universitetet i Oslo, Oslo University Hospital, Hesselman's Research, Astma- och Allergiförbundet, Health and Rehabilitation Norway, Konsul Th. C Bergh Foundation, Vårdalstiftelsen, Karolinska Institutet SFO-V, Hjärt-Lungfonden, The Norwegian Research Council, The Regional Health Board South East, Sykehuset Østfold and Vetenskapsrådet. Funding information for this article has been deposited with the Crossref Funder Registry.

Author contributions: C-A. Olsson Mägi carried out the data collection and data management, was responsible for the data analysis, and preformed and drafted the initial manuscript. A. Bjerg Bäcklund, C. Almqvist, K-H. Carlsen, K. Lødrup Carlsen, B. Granum, G. Haugen, C.M. Jonassen, E.M. Rehbinder, K.D. Sjøborg, H. Skjerven, A.C. Staff, R. Vettukattil, C. Söderhäll and B. Nordlund critically reviewed data analysis and revised the manuscript. B. Nordlund conceptualised and designed the study, and critically reviewed and revised the manuscript. All authors approved the final manuscript as submitted and agree to be accountable for all aspects of the work.

Conflict of interest: C-A. Olsson Mägi has nothing to disclose. A. Bjerg Bäcklund has nothing to disclose. K. Lødrup Carlsen has nothing to disclose. C. Almqvist has nothing to disclose. K-H. Carlsen has nothing to disclose. B. Granum has nothing to disclose. G. Haugen has nothing to disclose. K. Hilde has nothing to disclose. O.C. Lødrup Carlsen has nothing to disclose. C.M. Jonassen has nothing to disclose. E.M. Rehbinder reports honoraria for lectures from Sanofi Genzyme, Novartis, MEDA and Omega Pharma, outside the submitted work. K.D. Sjøborg has nothing to disclose. H. Skjerven has nothing to disclose. A.C. Staff has nothing to disclose. R. Vettukattil has nothing to disclose. C. Söderhäll has nothing to disclose. B. Nordlund has nothing to disclose.

\section{References}

1 World Health Organization. WHO recommendations on antenatal care for a positive pregnancy experience. www. who.int/reproductivehealth/publications/maternal_perinatal_health/anc-positive-pregnancy-experience/en/. Date last accessed: 14 March 2019; date last updated: 2016.

2 Lazarus RS, Folkman S, ed. Stress, Appraisal, and Coping. New York, Springer Pub. Co., 1984.

3 Yun S, Donovan MH, Ross MN, et al. Stress-induced anxiety- and depressive-like phenotype associated with transient reduction in neurogenesis in adult nestin-CreER.sup.T2/diphtheria toxin fragment A transgenic mice. PLoS One 2016; 11: e0147256.

4 Woody CA, Ferrari AJ, Siskind DJ, et al. A systematic review and meta-regression of the prevalence and incidence of perinatal depression. J Affect Disord 2017; 219: 86-92.

5 Cohen S, Kamarck T, Mermelstein R. A global measure of perceived stress. J Health Soc Behav 1983; 24: 385-396.

6 Solivan AE, Xiong X, Harville EW, et al. Measurement of perceived stress among pregnant women: a comparison of two different instruments. Matern Child Health J 2015; 19: 1910-1915.

7 Cohen S, Williamson GM. Perceived Stress in a Probability Sample of the United States. In: Spacapan S, Oskamp S, eds. The social psychology of health: Claremont Symposium on applied social psychology. Newbury Park, Sage, 1988; pp. 31-67. 

in Canada: from pregnancy through the preschool years. Can J Psychiatry 2019; 64: 190-198.

9 Kubo A, Ferrara A, Brown SD, et al. Perceived psychosocial stress and gestational weight gain among women with gestational diabetes. PLoS One 2017; 12: e0174290.

10 Lau Y, Tha PH, Wong DF, et al. Different perceptions of stress, coping styles, and general well-being among pregnant Chinese women: a structural equation modeling approach. Arch Womens Ment Health 2016; 19: 71-78.

11 Pinar SE, Aksoy OD, Daglar G, et al. Effect of stress management training on depression, stress and coping strategies in pregnant women: a randomised controlled trial. J Psychosom Obstet Gynaecol 2018; 39: $203-210$.

12 Beattie J, Hall H, Biro MA, et al. Effects of mindfulness on maternal stress, depressive symptoms and awareness of present moment experience: a pilot randomised trial. Midwifery 2017; 50: 174-183.

13 Kwon HL, Belanger K, Bracken MB. Asthma prevalence among pregnant and childbearing-aged women in the United States: estimates from national health surveys. Ann Epidemiol 2003; 13: 317-324.

14 Schatz M, Dombrowski MP, Wise R, et al. Asthma morbidity during pregnancy can be predicted by severity classification. J Allergy Clin Immunol 2003; 112: 283-2838.

15 Weatherhead S, Robson SC, Reynolds NJ. Eczema in pregnancy. BMJ 2007; 335: 152-154.

16 Carlsen KCL, Rehbinder EM, Skjerven HO, et al. Preventing Atopic Dermatitis and ALLergies in Children - the PreventADALL study. Allergy 2018; 73: 2063-2070.

17 Hohmann C, Pinart MF, Tischer C, et al. The development of the MeDALL Core Questionnaires for a harmonized follow-up assessment of eleven European birth cohorts on asthma and allergies. Int Arch Allergy Immunol 2014; 163: 215-224.

18 Bann CM, Parker CB, Grobman WA, et al. Psychometric properties of stress and anxiety measures among nulliparous women. J Psychosom Obstet Gynaecol 2017; 38: 53-62.

19 Rieger KL, Heaman MI. Factors associated with high levels of perceived prenatal stress among inner-city women J Obstet Gynecol Neonatal Nurs 2016; 45: 180-195.

20 Smew AI, Hedman AM, Chiesa F, et al. Limited association between markers of stress during pregnancy and fetal growth in 'Born into Life', a new prospective birth cohort. Acta Paediatr 2018; 107: 1003-1010.

21 Ahmed AE, Albalawi AN, Alshehri AA, et al. Stress and its predictors in pregnant women: a study in Saudi Arabia. Psychol Res Behav Manag 2017; 10: 97-102.

22 Shah M, Hasan S, Malik S, et al. Perceived stress, sources and severity of stress among medical undergraduates in a Pakistani medical school. BMC Med Educ 2010; 10: 10-12.

23 Amr M, Hady El Gilany A, El-Hawary A. Does gender predict medical students' stress in Mansoura, Egypt? Med Educ Online 2008; 13: 12

24 Carolan-Olah M, Barry M. Antenatal stress: an Irish case study. Midwifery 2014; 30: 310-316.

25 Goletzke J, Kocalevent RD, Hansen G, et al. Prenatal stress perception and coping strategies: insights from a longitudinal prospective pregnancy cohort. J Psychosom Res 2017; 102: 8-14.

26 Damron KR. Review of the relationships among psychosocial stress, secondhand smoke, and perinatal smoking. JOGN Nurs 2017; 46: 325-333.

27 Rohleder N. Stimulation of systemic low-grade inflammation by psychosocial stress. Psychosom Med 2014; 76: 181-189.

28 Namazy JA, Chambers CF, Schatz M. Safety of therapeutic options for treating asthma in pregnancy. Expert Opin Drug Saf 2014; 13: 1613-1621.

29 Pali-Schöll I, Namazy J, Jensen-Jarolim E. Allergic diseases and asthma in pregnancy, a secondary publication. World Allergy Organ J 2017; 10: 10.

30 Murphy VE. Asthma in pregnancy: a hit for two. Eur Respir Rev 2014; 23: 64-68.

31 Beau A-B, Didier A, Hurault-Delarue C, et al. Prescription of asthma medications before and during pregnancy in France: an observational drug study using the EFEMERIS database. J Asthma 2017; 54: 258-264.

32 Kemmett D, Tidman MJ. The influence of the menstrual cycle and pregnancy on atopic dermatitis. Br J Dermatol 1991; 125: 59-61.

33 Stensgaard A, Bindslev-Jensen C, Nielsen D, et al. Quality of life in childhood, adolescence and adult food allergy: patient and parent perspectives. Clin Exp Allergy 2017; 47: 530-539.

34 Hamilton EAA, Nowell AK, Harden A, et al. Conduct and reporting of acceptability, attitudes, beliefs and experiences of pregnant women in randomised trials on diet and lifestyle interventions: a systematic review. Eur $J$ Obstet Gynecol Reprod Biol 2018; 225: 243-254.

35 Olander EK, Atkinson L, Edmunds JK, et al. Promoting healthy eating in pregnancy: what kind of support services do women say they want? Prim Health Care Res Dev 2012; 13: 237-243.

36 Wennberg AL, Hornsten A, Hamberg K. A questioned authority meets well-informed pregnant women: a qualitative study examining how midwives perceive their role in dietary counselling. BMC Pregnancy Childbirth 2015; $15: 88$.

37 McEwen BS. Stress, adaptation, and disease. Allostasis and allostatic load. Ann N Y Acad Sci 1998; 840: 33-44.

38 Brydon L, Edwards S, Mohamed-Ali V, et al. Socioeconomic status and stress-induced increases in interleukin-6. Brain Behav Immun 2004; 18: 281-290.

39 Mako H, Mieko S, Hiroyuki S. Sleep quality and stress in women with pregnancy-induced hypertension and gestational diabetes mellitus. Women Birth 2014; 27: 190-195. 